\title{
Layout Design and Reconfiguration in a Collaborative Manufacturing Network
}

\author{
Maria Manuela Azevedo ${ }^{1,2}$, José António Crispim²,3 and Jorge Pinho de Sousa ${ }^{1,2}$, \\ ${ }^{1}$ Faculty of Engineering, University of Porto, Rua Dr. Roberto Frias, 4200-465 Porto, \\ Portugal \\ ${ }^{2}$ INESC TEC, Rua Dr. Roberto Frias, 4200-465 Porto, Portugal \\ \{mazevedo, jsousa\}@inesctec.pt \\ ${ }^{3}$ School of Economics and Management, University of Minho, Campus de Gualtar, 4710- \\ 057 Braga, Portugal \\ crispim@eeg.uminho.pt
}

\begin{abstract}
This study explores strategic agility of an automotive corporate group and its influence on facility layouts and operational performance. Strategic agility is viewed here as a firm's strategic intent to achieve agile operations through collaboratively deploying the layouts of a set of facilities, driven by a management focus on improving its responsiveness and adaptability to customers' requirements. Our "collaborative multi-facility layout problem" involves the physical organization of departments between and inside several facilities geographically dispersed, that collaborate in manufacturing a complex product in a given time window. The model proposed in this work allows us to analyse the benefits of new horizontal collaboration forms with respect to several objectives, namely costs (material handling inside and between facilities, re-layout) and adjacency between departments. A case study of a first tier supplier in the automotive industry shows the applicability potential of the approach to real-life problems. The results show that horizontal collaboration among the facilities can positively influence the performance of the corporate group as a whole, and that of each firm individually.
\end{abstract}

Keywords: Agile operations; multi-facility layout problems; multi-objective optimization; reconfigurable layouts; collaboration.

\section{Introduction}

In a more and more competitive world, companies easily recognize they need to permanently develop new and more sophisticated strategies, in order to maintain and increase their performance. The reconfiguration and continuous optimization of resources and production processes can be a way to reduce costs and increase their opportunities and profit [1]. The integration in Collaborative Networks $(\mathrm{CN})$ can also be an important step to make organizations more effective and agile as part of broader manufacturing systems, and this may be specially important for SMEs, due to their reduced dimensions and high vulnerability. In this context, one of the current big challenges for industry is clearly the permanent need for rapid reconfiguration of 
manufacturing enterprises, in response to changing requirements and opportunities [2]. In practice, the configuration of facility layouts comprises the physical organization (of departments, machines, workstations, storage spaces, etc) inside a plant, thus facilitating production and material handling, and allowing flexible and efficient operations [3].

In a more ambitious way, and as proposed in this work, the combination of design and reconfiguration of layouts for collaborative networks of facilities, can in fact help companies to be more flexible and competitive. Therefore, the main research question of this work can be stated as follows: "in a dynamic network of factories, what impact can sharing departments among facilities have on the flexibility level of this network and on each factory individually?"

To answer this question, we propose a mathematical model (a quadratic integer program) to be used in assigning projects of complex products to networks of facilities and in designing the layout of each specific facility. These networks can be viewed as a kind of Virtual Enterprises (VE). In fact, in our particular case, the facilities are part of a corporate group, and even if they are not fully independent from each other, they own all the other main characteristics of a VE.

The next section of the paper presents a brief state of the art on facility layout and network collaboration, as a way to position the contributions of the proposed model and to highlight its innovation. In the following sections the problem under study is described, followed by a presentation of the model. Then preliminary computational results are presented. The paper ends with some conclusions on the presented approach and with topics for future research.

\section{Literature Review}

The concept of Collaborative Network $(C N)$ is currently widely disseminated and recognized as an important instrument for the competitiveness and survival of organizations, specially in periods of turbulent socio-economic changes [2]. A CN is a network of a variety of entities (e.g. organizations and people), largely autonomous, geographically distributed, and heterogeneous in terms of operating environment, culture, social capital and goals, but that collaborate to better achieve common or compatible goals, thus jointly generating value, with interactions supported by computer networks [2]. In CNs, Virtual Organizations (VOs) are an important class, characterized in four dimensions as follows: space (physically dispersed), time (asynchronous), mode of interaction (electronic networks) and individual diversity (different) [4]. A particular case of VO is the Virtual Enterprises (VE), representing a temporary alliance of enterprises that come together to share skills or core competences and resources in order to better respond to business opportunities, and whose cooperation is supported by computer networks [2].

A rapid formation of VOs, when needed, and their adjustments to the specific requirements of a given emerging opportunity is of great importance and is frequently viewed as a requirement for agility, and used as a survival mechanism in face of market/society turbulence [1]. 
Strategic agility is viewed in the literature from quite different managerial perspectives (e.g., operations, information systems, marketing, human resources) [5]. For example [6] define agility as "a successful exploration of competitive bases (speed, flexibility, innovation proactivity, quality and profitability) thought the integration of reconfigurable resources and knowledge management to provide customer driven products and services in a fast changing market environment". Recently, [7] consider that agility is the project team's ability to quickly change the project plan as a response to customer or stakeholders needs, market or technology demands in order to achieve better project and product performance in an innovative and dynamic project environment.

In fact, given today's frequency of changes in business environments, it is more and more important for companies to be flexible as a way to respond quickly and dynamically to those changes. This response capability should also exist at a higher, corporate level, combining a plant-level and a network-level analysis that aims at understanding the continuous interaction between individual plants and their constituent networks [8].

In the context of this work, we aim at applying these concepts to extended facility layout problems (FLP), that in fact encompass various types of situations, such as the allocation of departments inside facilities [9] or machines inside departments [10]. This area has been studied from several different points of view, considering: the type of layout configuration (single row [11], multi-rows [12], multi-floor [13], cellular $[12], \ldots)$; the type of problem (department/machine allocation, product flows [10], routing [14], ...); the objectives (single [12] or multiple [15], minimizing costs [12] or distances [16], or maximizing adjacencies [17], profits [18], ...) and constraints (overlap, budget [18], areas [19], ...); the nature of the problem (static [10] or dynamic [17]) and solved by a large variety and combination of resolution approaches (exact methods [20], heuristics [21], ...).

Due to the large impact that the layout has in a manufacturing company, recent studies tend to add more and more features to the basic, traditional problems. This is e.g. the case of [10] that integrates the layout design (by the location of unequal-area machines with duplicates) and the product flows assignment problem (by assigning products to machines according to the product process route). The work by [17] is another example, they proposes a dynamic allocation of departments, considering multiple objectives (minimize total material handling costs (MHC) and re-layout costs, and maximize adjacencies), solving the problem with classical optimization methods and with population-based metaheuristics.

Although the FLP has been extensively studied (for some surveys see for example [22], [23], [11]), the majority of works deal with the design and reconfiguration of layouts at a single facility. The model proposed in this work intends to cover this gap, by simultaneously designing the layout of a group of facilities, and performing the allocation of products considering the whole network. Therefore, an innovation of our research comes from considering capacities in the transport of materials between facilities, and from allowing the possibility of performing changes along time. 
Moreover, the model allows the addition or removal of departments and facilities at different periods, thus providing a higher level of flexibility.

\section{Problem Description}

The automotive industry works with "projects" that are associated with specific models of a car. A project comprises several parts that are themselves composed by a group of materials or components (see Fig. 1).

The mathematical model proposed in this work considers a set of geographically separated facilities that can produce and store the same type of products and components. Each facility has more or less the same department structure, with the same type of equipment and machines. These facilities are served (and linked) by a distribution system that uses trucks to move the raw materials, components and products between the factories.
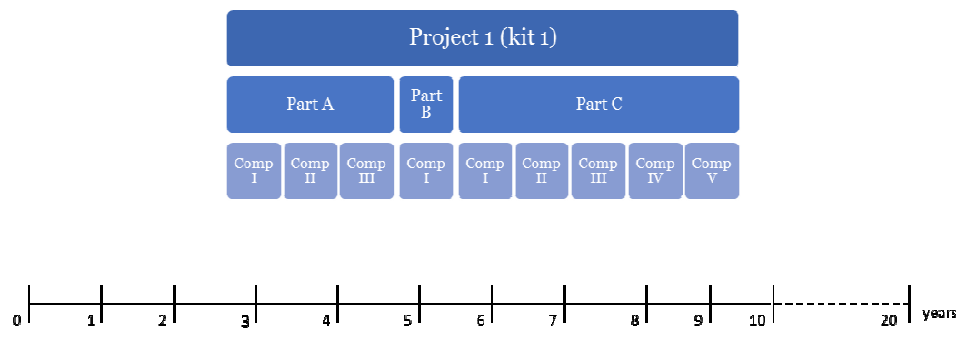

Production of complete kits

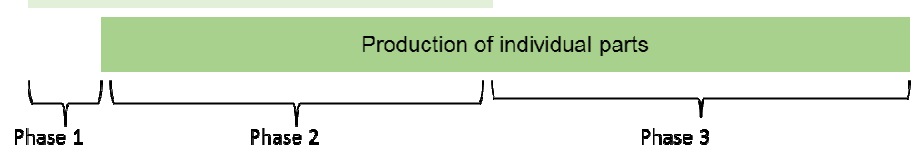

Fig. 1. Product complexity.

Given the high complexity of products, and the variety of requests from customers, in general collaboration between facilities is needed, with the formation of networks that change dynamically for each project.

In this context, our "collaborative multi-facility layout problem" involves the physical organisation of departments between and inside several geographically dispersed facilities, that collaborate in manufacturing a complex product in a given time window. The problem consists therefore in finding the best global layout for a given project. In order to optimise operations, we can use the flexibility of the system to exchange the location of departments between the facilities in different periods of time. 


\section{Model Description}

The model developed in this work (Fig. 2) provides firms with the ability to dynamically modify or reconfigure individual business processes to accommodate their actual and potential needs [24] by determining the best layout configuration of each facility, taking into account the project needs in each period, the available production capacity and the transportation capacities between facilities. The model also considers the possibility, along time, of adding or closing facilities (departments and sites), thus creating the flexibility for firms to quickly respond, by continuously adapting to changing business environments [25].
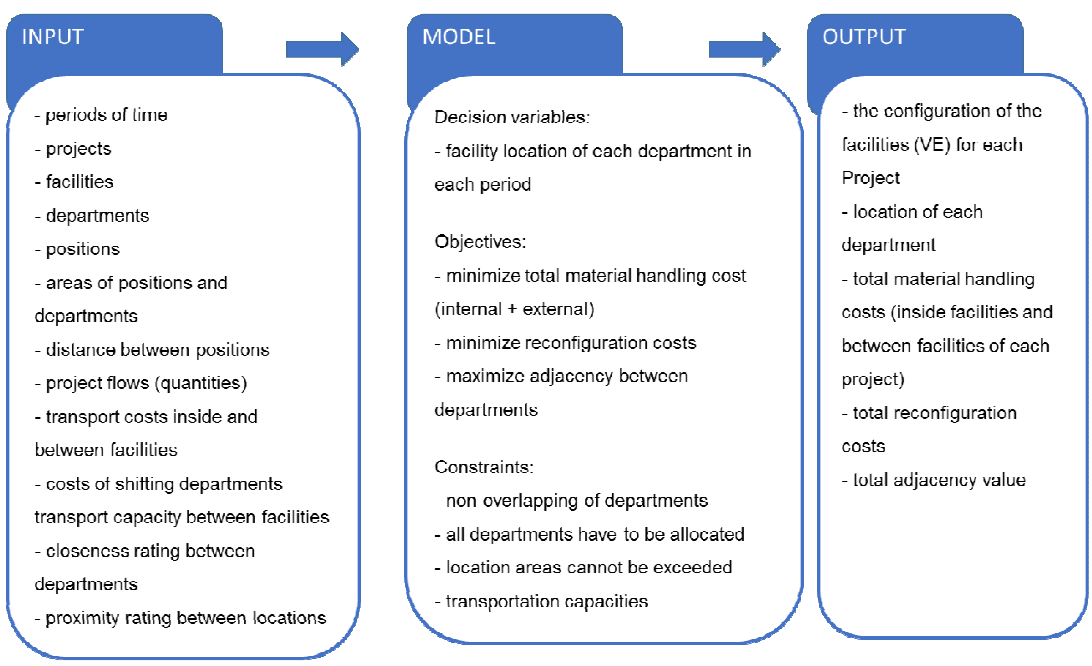

Fig. 2. Proposed model.

The formulation considered in this work is based on the Quadratic Assignment Problem (QAP), commonly used for dynamic layout problems [22]. Multiple objectives are considered, as defined by expression (1).

$$
\operatorname{Min} Z=\alpha \mathrm{MIIC}+\beta \mathrm{RC}-\gamma \mathrm{Adj}
$$

The objective "minimizing the total material handling costs $(M H C)$ " is commonly used in the literature of the unequal area FLP ([26], [27]). As [28] we assume fixed dimensions for facilities and the existence of several departments to be located inside facilities. We consider the total MHC as the sum of the internal and the external MHC 
of each project. This model considers also the "minimization of reconfiguration costs $(R C)$ " frequently used for layout reconfigurations (see e.g. [29] or [30]).

The objective "maximization of adjacency (Adj)" of the departments is based on a closeness rating (defining the importance of closeness between departments as proposed by [15]) and the proximity between the locations to where the departments are assigned. This is an important feature of the problem, due to the fact that when departments are allocated to different buildings, the relationships between them can be conditioned in different ways (e.g. imposing constraints on sharing the same specialized equipment or the same workers).

Our model adapts the constraints usually applied in the literature to solve unequal FLPs [21] to this multi-facility dynamic layout problem, namely: ensure that each position in a facility has at most one department, in each period; guarantee that each department is assigned only to one position, in each period; ensure that the area of a position is never exceeded by the department area assigned to it, in consecutive periods [20]; ensure that the existing capacity for transportation between facilities is never exceeded; check that the total number of existing locations is higher or equal to the total number of existing departments in each period; and confirm that only active departments are assigned to active locations in each period.

\section{Computational Results}

The performance of the proposed model was tested on some numerical instances based on a real case study briefly described below. Two situations have been considered, defined on the current case: first, by adding a new facility (test1); and, second, by closing one facility (test2). All the tests were made with the optimization software IBM ILOG Cplex V12.6, with a limit running time of 6 hours.

\subsection{Problem Data}

The case study motivating this work is based on a corporate group that produces plastic parts for the automotive industry. Initially $(t 1)$ there are 2 facilities $(f 1$ and $f 2)$, and since $t 2$ we consider a new facility $(f 3)$, with in total 13 locations to position the departments (Fig. 3). The distance between $f 1$ and $f 2$ is 30 , as well as between $f 2$ and $f 3$; the distance between $f 1$ and $f 3$ is 50 unit of distance.

For executing the movements between departments, we consider a distribution (transport) system based on the following assumptions: internal transport costs are constant along time and do not depend on the distances (5 cost units / unit of flow); external transport costs vary with time $(\mathrm{t} 1=20, \mathrm{t} 2=22, \mathrm{t} 3=25)$. The capacity of transport between facilities also vary $(\mathrm{t} 1=800, \mathrm{t} 2=1000$ and $\mathrm{t} 3=800)$.

There are 5 different types of departments: raw material warehousing; injection; assembly; painting; and product warehousing (Table 1). Due to characteristics and organization of the production, the areas assigned to each department can change in each period. We also consider that there some advantages in having departments of the same type (e.g. injection - A, B, C) together in the same facility (closeness level equal to 5). 


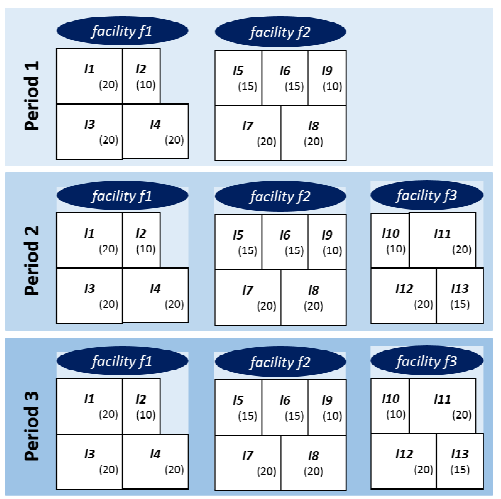

Fig. 3. Available area for the different facilities in each period of the horizon.

Table 1. Departments in the case study.

\begin{tabular}{|c|c|c|c|c|c|c|c|c|c|c|c|c|c|c|}
\hline \multirow[t]{2}{*}{ Departments } & & \multicolumn{3}{|c|}{$\begin{array}{c}\text { Raw } \\
\text { material } \\
\text { warehouse }\end{array}$} & \multicolumn{3}{|c|}{ Injection } & \multicolumn{3}{|c|}{ Assembly } & Painting & \multicolumn{3}{|c|}{$\begin{array}{c}\text { Product } \\
\text { warehouse }\end{array}$} \\
\hline & & $\mathbf{A}$ & B & C & D & $\mathbf{E}$ & $\mathbf{F}$ & G & H & I & $\mathbf{J}$ & $\mathbf{K}$ & L & M \\
\hline re-layout cost & & \multicolumn{3}{|c|}{5000} & \multicolumn{3}{|c|}{20000} & \multicolumn{3}{|c|}{10000} & 80000 & \multicolumn{3}{|c|}{5000} \\
\hline \multirow{3}{*}{$\begin{array}{c}\text { active } \\
\text { departments }\end{array}$} & $\mathrm{t} 1$ & 0 & 1 & 1 & 0 & 1 & 1 & 0 & 1 & 1 & 1 & 0 & 1 & 1 \\
\hline & t2 & 1 & 1 & 1 & 1 & 1 & 1 & 1 & 1 & 1 & 1 & 1 & 1 & 1 \\
\hline & $\mathrm{t} 3$ & 1 & 1 & 1 & 1 & 1 & 1 & 1 & 1 & 1 & 1 & 1 & 1 & 1 \\
\hline \multirow[t]{3}{*}{ area } & $\mathrm{t} 1$ & 0 & 10 & 20 & 0 & 20 & 20 & 0 & 15 & 10 & 20 & 0 & 15 & 20 \\
\hline & t2 & 10 & 20 & 20 & 15 & 20 & 20 & 10 & 15 & 10 & 20 & 15 & 15 & 20 \\
\hline & $\mathrm{t} 3$ & 10 & 20 & 15 & 15 & 20 & 15 & 5 & 15 & 5 & 20 & 15 & 15 & 20 \\
\hline
\end{tabular}

We consider there are 4 projects, in different life cycle phases: project 1 and 2 have a continuous production along the planning horizon; project 3 finishes in period $t 2$; and project 4 starts in period $t 2$ (Table 2 ).

Table 2. Project flows in each period.

\begin{tabular}{|c|c|c|c|c|c|c|c|}
\hline \multicolumn{3}{|c|}{ Periods } & \multirow[t]{2}{*}{ Project } & \multicolumn{4}{|c|}{ Flows between departments } \\
\hline $\mathrm{t} 1$ & $\mathrm{t} 2$ & $\mathrm{t} 3$ & & & & & \\
\hline$\checkmark$ & $\checkmark$ & $\checkmark$ & $\mathrm{P} 1$ & $\mathrm{C}->\mathrm{F}(500)$ & $\mathrm{F} \rightarrow \mathrm{J}(350)$ & $\mathrm{J} \rightarrow \mathrm{H}(200)$ & $\mathrm{H}->\mathrm{M}(200)$ \\
\hline$\checkmark$ & $\checkmark$ & $\checkmark$ & $\mathrm{P} 2$ & $\mathrm{~B}->\mathrm{E}(100)$ & $E->J(150)$ & $\mathrm{J}->\mathrm{H}(150)$ & $\mathrm{H}->\mathrm{L}(50)$ \\
\hline \multirow[t]{2}{*}{$\checkmark$} & $\checkmark$ & & P3 & $C \rightarrow F(100)$ & $\mathrm{F}->\mathrm{I}(100)$ & $\mathrm{I}->\mathrm{M}(50)$ & \\
\hline & $\checkmark$ & $\checkmark$ & $\mathrm{P} 4$ & $\mathrm{~A}->\mathrm{D}(50)$ & $\mathrm{D}->\mathrm{G}(150)$ & $\mathrm{G}->\mathrm{K}(100)$ & \\
\hline
\end{tabular}

Concerning the relative importance of the different objectives, we have considered the following weights (that should later be subject to some kind of sensitivity analysis): $35 \%$ for MHC; $35 \%$ for reconfiguration costs; and 30\% for adjacency. 


\subsection{Adding Facilities}

The occurrence of a new project (P4) in $\mathrm{t} 2$ allows us to explore the recourse to a new facility. Table 3 and Fig.4(test1) show the results obtained for this situation. Analysing these results, it is possible to conclude that:

- department J (painting) does not change along the horizon;

- facilities tend to become specialized in some phase of production (e.g. facility 2 focus on Assembly, Painting and Product warehouse; $f 1$ and $f 3$ focus on the first production phases, with Raw material warehouse, and Injection; and $f l$ at $t 3$ deals with all the product warehouses);

- project 4 rotates among the 3 facilities, apparently due to the smaller quantities to be produced;

- flows inside facilities are naturally higher, because the distances are lower, and the capacity to transport is not constrained, as it is the case for the transport between facilities;

- external MHC costs (1 542 400) are considerably larger than internal MHC costs (34 500);

- there are 3 reconfigurations occurring inside facilities, and 10 between facilities, with a total reconfiguration cost of 165000 and an adjacency value of 1015 .

Table 3. Results of test 1 - adding facility $f 3$ at $t 2$.

\begin{tabular}{|c|c|c|c|c|c|c|c|c|c|c|}
\hline \multirow[t]{2}{*}{ Project } & \multirow{2}{*}{$\begin{array}{l}\text { Network } \\
\text { structure }\end{array}$} & \multicolumn{3}{|c|}{ Flows inside facilities } & \multicolumn{5}{|c|}{ Flows between facilities } & \multirow[t]{2}{*}{ total MHC } \\
\hline & & $f 1$ & $f 2$ & $f 3$ & $f 1-f 2$ & $f 1-f 3$ & $f 2-f 1$ & $f 2-f 3$ & $f 3-f 2$ & \\
\hline P1 & $f 1, f 2 f 3$ & & & & & & & & & 650150 \\
\hline $\mathrm{t} 1$ & $f 1, f 2$ & 500 & 400 & & 350 & & & & & \\
\hline t2 & $f 3, f 2$ & & 400 & 500 & & & & & 350 & \\
\hline $\mathrm{t} 3$ & $f 2, f 1$ & & 1050 & & 200 & & & & & \\
\hline P2 & $f 1, f 2, f 3$ & & & & & & & & & 373900 \\
\hline $\mathrm{t} 1$ & $f 1, f 2$ & 100 & 200 & & 150 & & & & & \\
\hline $\mathrm{t} 2$ & $f 1, f 2$ & 100 & 200 & & 150 & & & & & \\
\hline t3 & $f 3, f 2$ & & 150 & 100 & & & & 50 & 150 & \\
\hline P3 & $f 1, f 2, f 3$ & & & & & & & & & 108650 \\
\hline $\mathrm{t} 1$ & $f 1, f 2$ & 100 & 50 & & 100 & & & & & \\
\hline t2 & $f 3, f 2$ & & & 200 & & & & & 50 & \\
\hline P4 & $f 1, f 2, f 3$ & & & & & & & & & 444200 \\
\hline t2 & $f 1, f 2, f 3$ & & & & & 50 & 100 & & 150 & \\
\hline $\mathrm{t} 3$ & $f 1, f 2, f 3$ & & & 50 & & & 100 & & 150 & \\
\hline & & 800 & 2450 & 850 & 950 & 50 & 200 & 50 & 850 & 1576900 \\
\hline $\mathbf{R e}$ & ayout costs & 1650 & & & $\mathrm{Ad}$ & acency & 1015 & & & \\
\hline
\end{tabular}

\subsection{Eliminating Facilities and Departments}

In order to understand the impact of eliminating a facility, we will consider that project 3 finishes in period $t 2$ (thus making departments B, E, I and L unnecessary) see Table 4 and Fig. 4 (test2). Analysing these results, it is possible to conclude that:

- facility f2 has always 3 types of departments for the last phases of production (Assembly, Painting, and Product warehouse); 
- departments $\mathrm{J}$ and $\mathrm{D}$ do never change along the planning horizon; and departments B, E, M, H and K only change inside the same facility;

- flows (see Table 4) are similar to test 1, for each facility and between facilities;

- external MHC costs (1 399 900) decrease and internal MHC costs (11 650) decrease too, when compared with test 1 ;

- this solution has less reconfigurations (5 inside facilities and 5 between facilities), with smaller reconfiguration costs than test1 (115000), and a lower value of adjacency (895).

Table 4. Results of test 2 - close facility $f 1$ at $t 3$.

\begin{tabular}{|c|c|c|c|c|c|c|c|c|c|c|}
\hline \multirow[t]{2}{*}{ Project } & \multirow{2}{*}{$\begin{array}{l}\text { Network } \\
\text { structure }\end{array}$} & \multicolumn{3}{|c|}{ Flows inside facilities } & \multicolumn{5}{|c|}{ Flows between facilities } & \multirow[t]{2}{*}{ total MHC } \\
\hline & & f1 & $f 2$ & f3 & $f 1-f 2$ & $f 1-f 3$ & $f 2-f 1$ & $f 2-f 3$ & $f 3-f 2$ & \\
\hline \multirow[t]{4}{*}{$\mathbf{P 1}$} & $f 1, f 2, f 3$ & & & & & & & & & 766800 \\
\hline & $f 1, f 2$ & 500 & 400 & & 350 & & & & & \\
\hline & $f 3, f 2$ & & 400 & 500 & & & & & 350 & \\
\hline & $f 2, f 3$ & & 900 & & & & & & 350 & \\
\hline \multirow[t]{3}{*}{$\mathbf{P 2}$} & $f 1, f 2, f 3$ & & & & & & & & & 247450 \\
\hline & $f 1, f 2$ & 100 & 200 & & 150 & & & & & \\
\hline & $f 1, f 2$ & 100 & 150 & & 150 & & 50 & & & \\
\hline \multirow[t]{3}{*}{$\mathbf{P 3}$} & $f 1, f 2, f 3$ & & & & & & & & & 143900 \\
\hline & $f 1, f 2$ & 100 & 50 & & 100 & & & & & \\
\hline & $f 3, f 2$ & & 50 & 100 & & & & & 100 & \\
\hline \multirow[t]{5}{*}{ P4 } & $f 1, f 2, f 3$ & & & & & & & & & 253400 \\
\hline & $f 1, f 2, f 3$ & & & 150 & & 50 & & & 100 & \\
\hline & $f 2, f 3$ & & 100 & 50 & & & & & 150 & \\
\hline & & 800 & 2250 & 800 & 750 & 50 & $\mathbf{5 0}$ & $\mathbf{0}$ & 1050 & 1411550 \\
\hline & ayout cost & 1150 & & & $\mathrm{Ad}$ & cency & 895 & & & \\
\hline
\end{tabular}
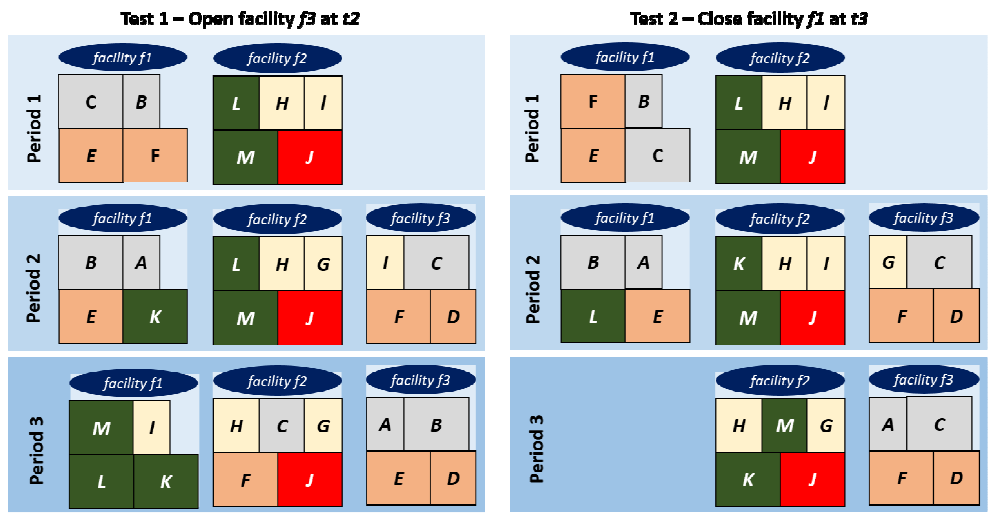

Fig. 4. Configuration of facilities, in test 1 and in test 2 . 


\subsection{Assessing Network Collaboration}

This model allows companies to evaluate, in different ways, the performance of the generated configurations: both for each facility and for the network formed for each project (in terms of flows, costs and time evolution) (see Fig. 5).

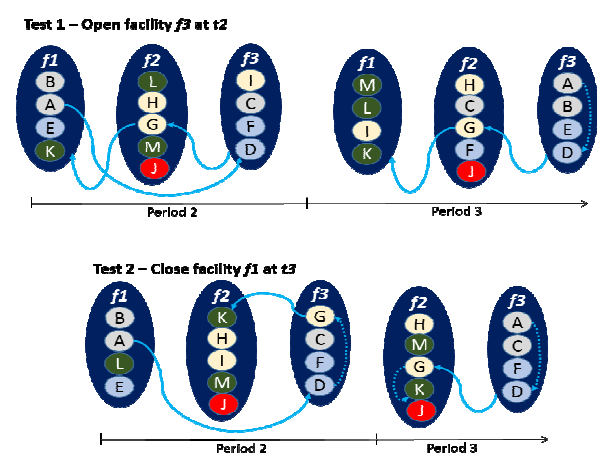

Fig. 5. Flows between facilities at Network of project $\mathrm{p} 4$.

Despite their preliminary nature, the results show the potential of inter facilities collaboration in manufacturing systems, and its role in dynamically adjusting the network structure to take into account the flows requirements in different periods of the planning horizon. These experiments also show the developed model can be used to adjust the firm's strategy in response to internal or external changes through facility layout collaboration.

\section{Conclusions}

This paper presents a model for supporting the definition of a collaboration strategy of different facilities or companies in a corporate group, to enhance its agility and responsiveness. For illustrative purposes, a case study was defined based on a first tier supplier in the automotive industry. The formation of collaborative networks involving the companies of the group may clearly improve manufacturing performance for the products and components of the different projects.

The model proposed in this work determines the layout configuration of all facilities, taking into consideration the flows between departments induced by the different projects. The model considers three objectives (minimize total material handling costs, minimize re-layout costs, and maximize the adjacency between departments) in order to better reflect the main prevailing concerns in real situations. The model was tested with two simplified instances inspired by real situations, namely: the emergence of a new project that requires a new partner; and the conclusion of a project leading to the end of that collaboration. These changes lead to the 
implementation of some layout reconfigurations, in different periods of the planning horizon.

In general terms, the model can be used to support the design and deployment of new configurations and layouts, based on advanced forms of collaboration, and thus promote the strategic agility of a corporate group. This will allow a higher adaptability to customer requirements (better handling demand fluctuations or changing location of facilities to be closer to customers) certainly improving global performance.

Acknowledgments. This research was partially financed by the North Portugal Regional Operational Programme (NORTE 2020), under the PORTUGAL 2020 Partnership Agreement, and through the European Regional Development Fund (ERDF), within the project "TEC4Growth - Pervasive Intelligence, Enhancers and Proofs of Concept with Industrial Impact / NORTE-01-0145-FEDER000020". The first author was also funded by the PhD grant SFRH/BD/33731/2009 from FCT, the Portuguese Foundation for Science and Technology (MIT Portugal Program).

\section{References}

[1] Afsarmanesh, H. Camarinha-Matos, L. M. Msanjila, S. S.: On management of 2nd generation Virtual Organizations Breeding Environments, Annu. Rev. Control, vol. 33, no. 2, pp. 209--219 (2009)

[2] Camarinha-Matos, L. M. Afsarmanesh, H. Galeano, N. Molina, A.: Collaborative networked organizations - Concepts and practice in manufacturing enterprises, Comput. Ind. Eng., vol. 57, no. 1, pp. 46--60 (2009)

[3] Azevedo, M. Crispim, J. Pinho de Sousa, J.: Flexible and Reconfigurable Layouts in Complex Manufacturing Systems, In Competitive Manufacturing for Innovative Products and Services: Proceedings of the APMS 2012 Conference, Advances in Production Management Systems, vol. 397, D. Emmanouilidis, C., Taisch, M., and Kiritsis, Ed. Springer, pp. 484--493 (2013)

[4] Vartiainen, M.: The functionality of virtual organizations, Proc. t-world 2001, Helsinki 13.9.2001 , pp. 273--292 (2001)

[5] Li, X. Goldsby, T.J. Holsapple, C.W.: Supply chain agility: scale development, Int. J. Logist. Manag., vol. 20, no.3, pp. 408--424 (2009)

[6] Yusuf, Y.Y. Sarhadi, M. Gunasekaran, A.: Agile manufacturing: the drivers, concepts and attributes, Int. J. Prod. Econ., vol. 62, no. 1, pp. 33--43 (1999)

[7] Conforto, E. C. Amaral, D.C. Silva, S.L. Felippo, A. Di. Kamikawachi, D.S.L.: The agility construct on project management theory, Int. J. Proj. Manag., vol. 34, no. 4, pp. 660--674 (2016)

[8] Cheng, Y. Farooq, S. Johansen, J.: International manufacturing network: past, present and future, Int. J. Oper. Prod. Manag., vol. 35, no.3, pp. 392--429 (2015)

[9] Aiello, G. Enea, M. Galante, G.: A multi-objective approach to facility layout problem by genetic search algorithm and Electre method, Robot. Comput. Integr. Manuf., vol. 22, no. 5-6, pp. 447--455 (2006)

[10] Taghavi, A. Murat, A.: A heuristic procedure for the integrated facility layout design and flow assignment problem, Comput. Ind. Eng., vol. 61, no. 1, pp. 55--63 (2011) 
[11] Keller, B. Buscher, U.: Single row layout models, Eur. J. Oper. Res., vol. 245, no. 3, pp. 629--644 (2015)

[12] Kia, R. Baboli, A. Javadian, N. Tavakkoli-Moghaddam, R. Kazemi, M. Khorrami, J.: Solving a group layout design model of a dynamic cellular manufacturing system with alternative process routings, lot splitting and flexible reconfiguration by simulated annealing, Comput. Oper. Res., vol. 39, no. 11, pp. 2642--2658 (2012)

[13] Kia, R. Khaksar-Haghani, F. Javadian, N. Tavakkoli-Moghaddam, R.: Solving a multifloor layout design model of a dynamic cellular manufacturing system by an efficient genetic algorithm, J. Manuf. Syst., vol. 33, no. 1, pp. 218--232 (2014)

[14] Kulturel-Konak, S.Smith, E. Norman, B.:Layout optimization considering production uncertainty and routing flexibility, Int. J. Prod. Res., vol. 42, no. 21, pp. 4475--4493 (2004)

[15] Jaafari, A. Krishnan, K. Hossein, S. Doulabi, H. Davoudpour, H.:A Multi-Objective Formulation for Facility Layout Problem, In World Congress on engineering and Computer Science, vol. II (2009)

[16] Koşucuoğlu, D. Bilge, U.: Material handling considerations in the FMS loading problem with full routing flexibility, Int. J. Prod. Res., vol. 50, no. 22, pp. 6530--6552 (2012)

[17] Emami, S. Nookabadi, A.S.: Managing a new multi-objective model for the dynamic facility layout problem, Int. J. Adv. Manuf. Technol., vol. 68, no. 9-12, pp. 2215-2228 (2013)

[18] Şahin, R. Ertoğral, K. Türkbey, O.: A simulated annealing heuristic for the dynamic layout problem with budget constraint, Comput. Ind. Eng., vol. 59, no. 2, pp. 308--313 (2010)

[19] Kulturel-Konak, S. Konak, A.: Unequal area flexible bay facility layout using ant colony optimisation, Int. J. Prod. Res., vol. 49, no. 7, pp. 1877--1902 (2011)

[20] Lacksonen, T.A.: Preprocessing for static and dynamic facility layout problems, Int. J. Prod. Res., vol. 35, no. 4, pp. 1095--1106 (1997)

[21] Wang, M.J. Hu, M.H. Ku, M.Y.: A solution to the unequal area facilities layout problem by genetic algorithm, Comput. Ind., vol. 56, no. 2, pp. 207--220 (2005)

[22] Drira, A. Pierreval, H. Hajri-Gabouj, S.: Facility layout problems: A survey, Annu. Rev. Control, vol. 31, no. 2, pp. 255--267 (2007)

[23] Moslemipour, G. Lee, T.S. Rilling, D.: A review of intelligent approaches for designing dynamic and robust layouts in flexible manufacturing systems, Int. J. Adv. Manuf. Technol. (2011)

[24] Raschke, R.L. David, J. S.: Business Process Agility Business Process Agility, (2005)

[25] Ganguly, A. Nilchiani, R. Farr, J.V.: Evaluating agility in corporate enterprises, Int. J. Prod. Econ., vol. 118, no. 2, pp. 410--423 (2009)

[26] Bozorgi, N. Abedzadeh, M. Zeinali, M.: Tabu search heuristic for efficiency of dynamic facility layout problem, Int. J. Adv. Manuf. Technol. (2014)

[27] S. Emami and A. S. Nookabadi, 'Managing a new multi-objective model for the dynamic facility layout problem', Int. J. Adv. Manuf. Technol., vol. 68, no. 9-12, pp. 2215-2228, Feb. 2013.

[28] Wong, K.Y.: Applying Ant System for solving Unequal Area Facility Layout Problems, Eur. J. Oper. Res., vol. 202, no. 3, pp. 730--746 (2010)

[29] Shahin, A. Poormostafa, M.: Facility Layout Simulation and Optimization: an Integration of Advanced Quality and Decision Making tools and Techniques, Mod. Appl. Sci., vol. 5, no. 4, (2011)

[30] McKendall, A.R. Hakobyan, A.: Heuristics for the dynamic facility layout problem with unequal-area departments, Eur. J. Oper. Res., vol. 201, no. 1, pp. 171--182 (2010) 